\title{
MATERIALIDADES Y MEMORIAS COLECTIVAS EN LA COMUNIDAD PUEBLO TOLOMBÓN (VALLE DE CHOROMORO, ARGENTINA)
}

\author{
Materialities and Collective Memories in the Tolombón People Community
}

(Choromoro valley, Argentina)

\section{MACARENA MANZANELLI*}

\section{Fecha de recepción: 27 agosto de 2020 - Fecha de aprobación: 28 de junio de 2021}

\section{Resumen:}

En un contexto de incremento de los conflictos territoriales durante los últimos cinco años, la comunidad Pueblo Tolombón (valle de Choromoro, departamento de Trancas, Tucumán, Argentina) impulsó procesos de reconocimiento identitario y revitalización territorial. Analizo la resignificación de materialidades en el marco de dicho proceso: formas de conservar las materialidades, sus roles y vínculos. Me baso en el proyecto de resguardo de materialidades y creación de espacios de memoria. Parto de la idea de que las materialidades se encuentran cargadas de sentido y poseen distintas valoraciones de acuerdo con los tipos de intercambios. Concluyo que hubo una resignificación de las materialidades: de no ser conservadas a hacerlo de forma colectiva y como reservorios de memoria sagrados. Asimismo, también se dio una revalorización del sentido de pertenencia identitario y territorial a medida que el Pueblo Tolombón cuestionó categorías identitarias hegemónicas deslegitimadoras. Las reflexiones desarrolladas son producto del trabajo de investigación etnográfico realizado durante los años 2017-2019.

Palabras clave: Pueblo Tolombón; materialidades; memoria colectiva; conflictos territoriales.

\section{Abstract:}

In a context of increasing territorial conflicts during the last five years, the Tolombón community-Pueblo (Choromoro valley, Department of Trancas, Tucumán, Argentina) promoted identity and territorial recognition processes. I analyze the resignification of materialities within the framework of this process: ways of preserving materialities, their roles and links. I am based on the project for the protection of materialities and the creation of memory spaces. I start from the idea that materialities are loaded with meanings and have different valuations according to the types of exchanges. I conclude that there was a resignification of the materialities, from not being conserved to doing it collectively and as sacred memory reservoirs. Likewise, a revaluation of their sense of identity and territorial belonging as Pueblo Tolombón questioned delegitimizing hegemonic identity categories. The reflections developed are the product of ethnographic research work during the years 2017-2019.

Keywords: Tolombón People; collective memory; materialities; territorial disputes.

\footnotetext{
* Dra. en Ciencias Sociales y Humanas. Investigadora CONICET / Departamento de Derecho y Ciencias Políticas, Universidad Nacional de La Matanza, Argentina. El artículo se enmarca en el Proyecto PROINCE D059 "Pueblos originarios y territorio: Sentidos, relacionalidad, conflictos, reclamos y derechos", radicado en el Departamento de Derecho y Ciencia Política, Universidad Nacional de la Matanza por medio del Programa de Incentivos a Docentes Investigadores de la Secretaría de Políticas Universitarias. Correo-e: mmanzanelli@unlam.edu.ar
} 


\section{Introducción}

Las situaciones de litigio centradas en el acceso y usos de la tierra, territorios y sus bienes ha atravesado históricamente a los pueblos originarios en Argentina, como ocurre en en la región del noroeste argentino y en el caso desarrollado en este trabajo: el de la comunidad diaguita Pueblo Tolombón. Este recorrido de larga duración se inició con la conquista española, cuando los y las tolombones fueron extrañados desde el valle Calchaquí al valle de Choromoro, y continuó hasta la actualidad con el incumplimiento de los derechos territoriales formalmente promulgados (López, 2006).

Hacia el año 2015, los conflictos territoriales en la Comunidad Indígena Pueblo Tolombón se incrementaron. Entre las más de ochenta causas judiciales -algunas de ellas penales-, tal como se detallará más adelante, sobresalen la quema intencionada del quincho comunitario en la base Gonzalo (año 2016) por parte de los terratenientes 1 Critto; la pérdida de un cerco comunitario por parte de la familia Cayata, uno de cuyos miembros era la autoridad-cacique de ese momento (año 2016) y el tercer intento de desalojo del comunero Donato Nievas por los terratenientes López de Zavalía ocurrido en el año 2017, el cual contó con el aval de la Corte Suprema de la provincia de Tucumán, en ignorancia del marco de derecho nacional e internacional indigenista.

Ante el recrudecimiento de las amenazas e intentos de desalojos, los y las comuneras decidieron, en asambleas comunitarias, desarrollar acciones que revirtiesen el modo en que su posesión territorial era significada desde los sectores de poder, mismos que los acusaban de ocupación ilegítima de los territorios. En consecuencia, en el marco de un proceso de reorganización comunitaria y de reconocimiento identitario, los y las tolombones resignificaron su cultura material junto a la reelaboración de memorias colectivas y de la verbalización de recuerdos sobre cómo sus antepasados-mayores y ancestros han ocupado y defendido el territorio. Uno de estos proyectos fue la planificación de un sitio de memoria comunitario. El fin de la construcción de este espacio es el resguardo en forma colectiva de los vestigios arqueológicos presentes a lo largo de su territorio -sitios, vasijas y tiestos cerámicos, instrumentos de piedra, restos mortales, utensilios, entre otros-.

En este artículo analizo estos procesos de resignificación de materialidades y de creación de espacios de memoria indagando en las formas de resguardar distintos elementos materiales -vasijas y tiestos cerámicos, instrumentos de piedra, restos mortales, utensilios, pircas, entre otros- presentes a lo largo de su comunidad y de conocer las memorias y los relatos entrelazados con nociones de ancestralidad y de defensa del territorio. Me interesa narrar las trayectorias que han tenido estas materialidades, los contextos en los que han sido significadas, qué rol han asumido y los vínculos entablados.

Las prácticas e iniciativas fueron identificadas a partir del trabajo etnográfico con técnicas de observación participante y entrevistas semiestructuradas durante los viajes realizados al territorio durante los años 2017 (julio-agosto), 2018 (enero-febrero; julio-agosto) y 2019 (enero) en el marco de una investigación doctoral. Brevemente, mi recorrido comenzó cuando conocí a comuneros, comuneras y autoridades que participaron en la actividad "Encuentro Intercultural 
de Cerámica en Chuschagasta - Reafirmando la Identidad Diaguita. Inauguración del taller de Cerámica Javier Chocobar" en la comunidad vecina Los Chuschagasta (año 2017). Allí la autoridad tradicional del Pueblo Tolombón, Rufino Morales, ofreció una charla junto a Andrés Mamaní, autoridad de Los Chuschagasta, sobre piezas de cerámica encontradas y los significados de su iconografía.

Si bien las piezas cerámicas estuvieron presentes desde el primer momento, mis ejes de investigación y, por lo tanto, los registros de campo y entrevistas se centraron en un principio en el proceso de autorreconocimiento, de reorganización comunitaria y en la historia de los conflictos territoriales. No obstante, tal como es la construcción del trabajo de campo, dinámico y sorprendente (Guber, 2011), a medida que conviví y compartí distintas actividades con los y las comuneras, las materialidades comenzaron a tomar mayor protagonismo. A partir del segundo viaje, comencé a indagar cómo eran las prácticas diarias en el territorio y me focalicé en cómo el espacio estaba siendo habitado. Recorrí las distintas bases de la comunidad y conocí que había un museo en la base de Hualinchay. Luego, durante mi tercera estadía en la base de Potrero, comencé a observar que distintos elementos materiales recuperados en la zona -restos de ollitas, tinajas, urnas, morteros, entre otras piezas, mayormente de cerámica-, estaban en constante interacción con los y las comuneras, acompañados de relatos sobre sus apariciones. De esta forma, mis registros y entrevistas se comenzaron a focalizar en profundizar más sobre sus significados e interacciones.

El orden de la presentación de este artículo está dirigido, en primer lugar, a indicar el marco teórico sobre territorios, materialidades, cultura material y memorias comunitarias desde el cual analicé estas iniciativas. Luego presento a la comunidad diaguita Pueblo Tolombón y los conflictos territoriales que históricamente perciben. En tercer lugar, refiero al tratamiento de las materialidades a partir de la identificación de tres momentos, que parten primero por no ser conservadas hasta la decisión de planificar un proyecto de resguardo colectivo y la creación del sitio de memoria con la emergencia de recuerdos que suscitó. Concluyo con las reflexiones elaboradas a partir de lo desarrollado.

\section{Territorio, materialidades y memorias colectivas}

Desde fines del siglo XX y comienzos del XXI, distintas disciplinas -geografía crítica, geopolítica o geografía del poder, disidente y cultural, antropología cultural, historia, arqueología posprocesual y museología- han replanteado la noción de territorio, objetos/materialidades y cultura material. Estos nuevos enfoques posibilitan que las investigaciones sociales puedan analizar, de una manera enriquecedora y crítica, fenómenos que han ganado visibilidad en las últimas cuatro décadas a partir de cambios en el nuevo marco de derecho de reconocimiento a las diversidades culturales, tales como los que se desarrollan en este artículo: materialidades, cultura material y memorias ${ }^{2}$ (Kopytoff, 1986; Myers, 1996; Miller, 2005; Benedetti, 2011; Maidana, 2011; Altschuler, 2013).

Desde estas visiones, por un lado, la noción de territorio fue redefinida al considerar no solo sus aspectos topográficos-naturales, sino también simbólicos, culturales y políticos. En este sentido, el territorio comenzó a ser enten- 
dido como una construcción sociohistórica y no como un mero espacio-medio dado o a priori. Asimismo, emergieron otros conceptos, como el de de espacio vivido, es decir, las representaciones que adquiere el espacio y sus relaciones de poder intrínsecas (Lefebvre, 1991 [1974]; Escobar, 2000; Lopes de Souza, 2001; Haesbaert, 2004; Schneider \& Peyré Tartaruga, 2006; Maidana, 2011). Este nuevo enfoque permitió incluir otras prácticas de territorialización -selección de elementos/objetos representativos y marcaciones del territorioimpulsadas por colectivos subalternizados, es decir, como formas de reapropiación material y simbólica del territorio (Ataliva, 2008; Barabas, 2014; Tamagno, Maidana \& Martínez, 2015), y no solo las autorizadas por actores estatales y privados dominantes.

Por otro lado, hubo reconsideraciones en la forma de analizar las materialidades y, en sí, la cultura material-elementos materiales (cosas, objetos, artefactos) e inmateriales, inmersos en una red de sentidos, clasificados y valorados de acuerdo con criterios negociados por los miembros de los colectivos, no sin conflictividades- (Kopytoff, 1986; Myers, 1996; Acuto \& Salvi, 2015). Desde un enfoque predominante -economicista objetivo- se establecieron dicotomías entre objetos y personas, siendo los primeros caracterizados de forma estática, pasiva y exógena. Asimismo, los objetos eran entendidos como mercancías con un valor de uso y de cambio $-\mathrm{y}$ sus derechos- o como simples indicadores de cronología, áreas culturales, actividades, culturas y tipologías (Kopytoff, 1986; Miller, 2005; Acuto \& Salvi, 2015; Huircapán, Jaramillo \& Acuto, 2017) ${ }^{3}$.

Nuevas perspectivas entienden que toda experiencia, que es simultáneamente corporal y cognitiva, tiene lugar en un contexto material que modela las interacciones, la subjetividad y los cuerpos. Los objetos se encuentran significativamente constituidos, poseen carácter performativo, es decir, que a medida que son usados y/o transformados también transforman a las personas (Miller, 2005; Acuto \& Salvi, 2015). Estos estudios se focalizaron en la noción de materialidades relativas, es decir, cómo los objetos son valorizados (ya sea como mercancías, tesoros o piezas de arte) y clasificados y en sus transformaciones y dinámicas (por ejemplo, en las categorías de valor, de ser inalienable a mercatilizado), vinculadas a lógicas de reproducción políticas y a la producción de jerarquías (Kopytoff, 1986; Myers, 1996; Miller, 2005). Me interesa resaltar tres ideas principales sobre las materialidades: los distintos estatus que pueden adquirir en ciclos de intercambios; las formas de gestión y la disposición de los objetos; y como reservorios de memoria.

En primer lugar, las materialidades se enmarcan en contextos culturales, sociopolíticos y económicos. Podemos encontrar diversas biografías de las cosas, con sus distintos aspectos sociales, culturales, relacionales, técnicos, legales, entre otros, que habilitan a preguntarse de dónde provienen, quién las hizo, sus trayectorias o edades, la variación de sus significados, cómo son resignificadas y sus ciclos de intercambios. Entre estos aspectos, la cuestión del estatus remite a los contextos cognoscitivos y culturales dinámicos en que son valoradas, clasificadas e intercambiadas.

En este sentido, algunos elementos pueden ser considerados sagrados o singularizados -inalienables- de acuerdo con el proceso de simbolización subyacente, es decir, la capacidad de intercambiarlos o de retenerlos 
(Myers, 1996). La acción de simbolización y los sentidos asignados son los que desplazan al objeto de esferas de mercantilización, así como también los puede remercantilizar. La investigadora Katherine Verdery (1999) señala que el carácter sagrado que adquiere un fenómeno/objeto -en su caso, estatuas que representan a personas fallecidas- ocurre cuando ha sido simbolizado como especial y digno de recordar por una comunidad, lo que lo vuelve capaz de transcender la temporalidad a la cual responden los hechos conmemorados. Por ejemplo, determinados elementos pueden ser concebidos como representativos y dignos de preservar y, por lo tanto, ser seleccionados para marcar el territorio -marcadores de identidad-, ya que evocan eventos que son resignificados a la luz de los acontecimientos presentes (Verdery, 1999).

En segundo lugar, se encuentra la gestión de estos objetos. Como señalé, los contextos en que los objetos son valorados -sus ingresos y permanencias en esferas de intercambiopermiten entender cómo son dispuestos por parte de los miembros de una sociedad y sus distintos colectivos. Entre estos espacios se encuentran los museos. La visión tradicional los concibe como una muestra de colecciones donde se exhiben objetos ordenados en vitrinas, junto a cédulas con información técnica sobre su origen y funcionalidad y donde se presenta un guion museográfico (Morales \& Quiroz, 2017). Este guion se conecta adecuadamente con las categorías configuradas desde el Estado y sus leyes para, mediante la disposición de las cosas, ejercer control sobre el territorio y la población, lo que genera efectos en los tipos de colectivos a los que interpelan y sus subjetividades. Bajo éste subyacen lógicas de etnogubernamentalidad -unicidad, linealidad y progreso-, en las que los objetos han sido usados como emblemas o marcas culturales que permiten unir distintas características y lugares a poblaciones.

Asimismo, el control del pasado es y ha sido un espacio de disputa entre el Estado y los colectivos subalternizados, lo cual queda reflejado en las reivindicaciones y demandas étnicas vinculadas con el patrimonio arqueológico (Acuto \& Salvi, 2015). De esta forma, el rol que asumieron las materialidades en tanto expresiones de una identidad étnica, es decir, diacríticos, en los términos de Barth (1976), permiten establecer límites territoriales y de procesos de difusión cultural. Las materialidades han sido funcionales a la forma en que los procesos etnogubernamentales de las últimas cuatro décadas han interpelado a los pueblos originarios.

Entre las leyes que gestionan las formas de ocupar el espacio se encuentra el Programa de Relevamiento Territorial, generado en el marco de la Ley Nacional 26.160. Entre los principios que subyacen en este programa se presenta el de "autoctonía" -tal como las agencias estatales han definido la relación con los restos arqueológicos presentes a lo largo del territorio- que se encuentran en estrecha vinculación con los procesos de reconocimiento identitario impulsados $^{4}$. A medida que los objetos circulan por la arena pública-estatal, donde se percibe que tienen el potencial económico y cultural para abordar el "problema aborigen", se transforman en productos y luego en muestras de las bellas artes, supuestamente vaciadas de etnicidad (Myers, 1996, p. 11).

En contraste, las teorías sostenidas desde la museología crítica y decolonial han repensado la gestión y la disposición de los objetos. Entre 
las principales acciones destacan el desbaratamiento de los modelos eurocéntricos para que sean los propios actores quienes señalen qué exponer y de qué manera (Bermejo \& Cortés Aliaga, 2019). Estas experiencias también recuperan la idea de que las materialidades se encuentran embebidas de sentidos, es decir, eso que le otorga el valor de ser algo determinado en un pueblo o comunidad, acompañado de narrativas, y que denominamos como patrimonio cultural inmaterial (Salazar \& Salvi, 2015). En este sentido, han surgido experiencias de museos comunitarios no exentas de conflictos. En algunas de ellas, la contradicción se manifiesta en que reproducen las mismas lógicas de los museos tradicionales con sus divisiones cronológicas y estratigráficas científicas (Puebla \& Ramírez, 2020).

No obstante, la potencialidad de estos enfoques se encuentra en que han permitido salir del orden dicotómico impuesto por la visión occidental y comprender que hay otros órdenes o redes de relación posibles, en los que coexisten y participan una proliferación de objetos y singularidades con otros objetos y personas relacionados entre sí a partir de una red de correspondencia que permiten ordenarlos. De esta forma, es posible entender diversas interpretaciones de los pueblos originarios que dan cuenta de sus propias prácticas culturales y materiales como pruebas no tanto de un pasado indígena arcaico, sino de la continuidad del poblamiento y del carácter ascendiente originario de los actuales habitantes. Además, incluyen otras formas de expresar la ocupación territorial, al remarcar modalidades de desplazamiento en el espacio, las cuales habían sido coartadas por las intervenciones estatales, y al apelar a nociones de espiritualidad propias de su cosmogonía (Escolar,
2003; Crespo, 2011). Asimismo, permiten visibilizar que las materialidades participan de estos espacios de disputa entre identidades que aspiran a imponer sus memorias e historias y sus legítimos reclamos territoriales o sobre recursos puntuales, a la vez que intentan invisibilizar a otras (Acuto \& Flores, 2019).

En tercer lugar, los elementos de la cultura material, al encontrarse relacionados con la identidad, la cultura, las tradiciones y la historia de un colectivo, actúan mnemónicamente como reservorio de memoria (Miller, 2005; Salazar \& Salvi, 2015; Acuto \& Flores, 2019). En torno a las materialidades emergen narrativas, recuerdos y saberes que forman parte de los objetos; prácticas que adquieren registro en los cuerpos, que los guían en su cotidianeidad y que se materializan. Se activan proyectos de recuperación y de restauración de conocimientos y experiencias sobre el pasado (Ramos, Tozzini \& Crespo, 2016). Entre ellos, recuerdos fragmentados, olvidos y silencios que han sido interpelados por narrativas dominantes que han deslegitimado y violentado a los pueblos originarios. De esta manera, las materialidades pueden ser entendidas como lugares de apego-afectivo y de enunciación que habilitan a reestablecer también aquellos recuerdos oprimidos, fragmentados o discontinuos, esos silencios y/u olvidos, entendidos como vacíos llenos de sentidos dado que evocan violencias y atropellamientos sufridos que no pueden ser enunciados (Pizarro, 2006; Lanusse, 2007; Crespo, 2018; Ramos, Crespo \& Tozzini, 2016).

A medida que las materialidades, como objetos portadores de identidad, son entendidas en amplios ciclos de intercambios $y$ valoraciones, se amplían las personas identifi- 
cadas a través de su circulación y, por lo tanto, las luchas políticas por reclamar su identidad aferrándose a categorías de materialidades valiosas o formas de propiedad (Myers, 2005). Ello sucede especialmente en contextos de conflictos y violencias políticas, puesto que se disputa el control y la legitimidad del pasado. En este proceso se valorizan las voces subalternizadas y sus conocimientos en torno a los usos y la producción de la cultura material y, así, múltiples conocimientos, afectos, prácticas y tradiciones heredadas del pasado que, al ser recordadas en grupo, la moldean a su vez (Longo, 2010; Ramos, 2016; Ramos, Tozzini \& Crespo, 2016; Jelin, 2004, 2017; Delrio, 2010). En otras palabras, en este proceso de ahondar en el pasado el presente lo recrea, por lo que se trata de un proceso en constante devenir, que se reactualiza de acuerdo con los hechos y acontecimientos vividos (Ramos, Crespo \& Tozzini, 2016, p. 20; Enderé \& Chaparro, 2013; Salazar \& Salvi, 2015; Corimayo \& Acuto, 2015; Chaparro, 2019).

En suma, se evidencia que no hay una única forma de concebir el territorio, tal como lo sostienen miradas esencialistas y dicotómicas, es decir, la idea de un espacio exteriorizado o separado de la persona, propia de un pensamiento occidental-moderno-instrumentalista. A su vez, la cultura material y las materialidades son entendidas como bienes cargados de significados, que interactúan y poseen incidencia en las experiencias de las personas al contener saberes, prácticas y memorias-hábito, que las guían en su cotidianeidad. En consecuencia, estas miradas permiten recuperar las visiones y prácticas de sectores que históricamente han sido subalternizados y desplazados de sus territorios.

\section{La comunidad Pueblo Tolombón}

La comunidad Pueblo Tolombón pertenece al Pueblo-Nación Diaguita. Se encuentra ubicada en el Segundo Distrito del Departamento de Trancas, valle de Choromoro, dentro de la microrregión Cuenca Tapias-Trancas, al noroeste de la provincia de Tucumán. La Comunidad Indígena Pueblo Tolombón responde burocrática y administrativamente tanto a la comuna de Choromoro -bases Gonzalo y Potrero, a detallar en las líneas siguientes-como a la de San Pedro de Colalao -bases Rearte, Tacanas Chicas, Tacanas Grandes y Hualinchay-. Desde el año 2001 , los y las tolombones cuentan con el reconocimiento estatal a través de su inscripción en el Registro Nacional de Comunidades Indígenas (Re.Na.Cl) como Comunidad Indígena Pueblo Tolombón con personería jurídica № 053/2001 y relevamiento territorial № 576 .

La comunidad Tolombón limita hacia el este con la Comunidad Indígena Los Chuschagasta, al sur con la Comunidad Indígena Potrero Grande, al norte con la Comunidad Indígena Indio Colalao y al oeste con la Comunidad Indígena Amaicha del Valle. La comunidad es contigua a Chuschagasta. Se organiza en diez bases, seis de ellas territoriales: Potrero, Gonzalo, Rearte (o Rearte Sur), Tacanas Grandes, Tacanas Chicas y Hualinchay; y cuatro bases de apoyo: tres en Tucumán (Los Nogales, El Cadillal y Tafí Viejo) y una en el sur del Conurbano Bonaerense (Temperley, provincia de Buenos Aires) (ver Figura 1).

Para llegar a Tolombón se puede elegir la opción sur, es decir, continuando desde La Higuera (comunidad Los Chuschagasta) veintidós kilómetros por la ruta provincial № 312. El recorrido se puede realizar por medio 
de un colectivo de la empresa San Pedro de Colalao. Otro camino para llegar a Tolombón es por el lado norte, viajando desde la ciudad San Pedro de Colalao hasta la base territorial Hualinchay con un colectivo, a caballo o en moto; o por la ruta provincial № 311 desde la base de Rearte, pasando por Tacanas Chicas, Tacanas Grandes hasta Hualinchay. Pueblo Tolombón está compuesto de aproximadamente 300 familias reconocidas y censadas, que residen en las seis bases territoriales y en las bases de apoyo. En cuanto a las bases territoriales, y de acuerdo con el último censo realizado ${ }^{5}$, en Potrero, Gonzalo y Tacanas Chicas se encuentra la mayor cantidad de familias, las que suman 200 comuneros y comuneras aproximadamente. Luego, en las bases de Rearte y de Tacanas Grandes viven alrededor de 15 familias y en Hualinchay unas 85.

Todas las bases cuentan con un servicio de colectivo de línea rural que las comunica con la ciudad de San Miguel de Tucumán, San Pedro de Colalao y Trancas, excepto la base de Rearte. Tiempo atrás había un ómnibus que realizaba el recorrido Gonzalo-Rearte-Tacanas Grandes por la ruta № 311, pero al ser poco utilizado dejó de prestar el servicio. No obstante, desde "el cruce" de las rutas № 312 y 311 , en la entrada de Gonzalo, es posible llegar a Rearte ya sea en auto, a caballo, en moto o a pie. En general, todas las bases cuentan con servicios de luz eléctrica y almacenes, excepto una de "las bandas" del río Gonzalo, también llamado Las Lechuzas, donde el tendido eléctrico aún no se encuentra disponible.

La Comunidad Indígena Tolombón posee numerosos e históricos conflictos por la posesión y tenencia de las tierras y territorios. Dada la extensión de este y la presencia de varias familias terratenientes, hacia el año 2019 contaba con más de ochenta conflictos territoriales y causas judiciales, incluyendo penales. Estos conflictos deben ser analizados como procesos de larga duración tanto por su origen histórico -inmersos en tramas de desigualdad y subalternizacióncomo por los distintos cambios que han presentado en las instancias judiciales -incluyendo sobreseimientos- que, sin embargo, no revirtieron en la práctica la situación de inseguridad jurídica a la que se encuentran expuestos los y las tolombones.

En la base de Potrero, los y las comuneras relataron despojos que datan de hace aproximadamente sesenta años, cuando fueron obligados con intimidaciones a desalojar sus cercos y casas, "perdiéndolo todo", animales y cosechas. Las familias terratenientes de la zona han sido los López Pondal y Critto, dueños de la finca denominada Las Criollas, ubicada entre las bases Gonzalo y Potrero; y la familia Alurralde-Paz, asentada cerca de la comunidad vecina de Rodeo Grande. Actualmente, esta base no presenta conflictos territoriales con causas judiciales activas.

En la base Gonzalo, desde fines de la década de 1990 y comienzos de la de 2000, se han presentado numerosas situaciones de hostigamientos, amenazas y hechos violentos que han sido judicializadas y cuyas causas, en su mayoría, se mantienen activas hasta el día de hoy. Podemos mencionar, por ejemplo, el caso de la comunera Justina Velardez contra la familia terrateniente Critto por el intento de desalojo y quema de parte del "bosque nativo" ubicado detrás de su casa. También, desde el año 2005 en adelante, el conflicto del comunero Don Santos Ríos, quien fue demandado por la familia terrateniente Guerinao -familiares de los 
terratenientes Critto- por la "mesada" -planicie utilizada como cerco de siembra comunitario compartido por las familias comunerasubicada en una de las lomas de Gonzalo.

En el mismo año, el comunero Román Ríos y su esposa Francisca Méndez tuvieron que sortear un intento de desalojo por parte de la familia terrateniente Critto. Luego, en noviembre de 2016, a la familia Cayata -uno de cuyos miembros, Jorge González, ocupó el cargo de autoridad tradicional-cacique- le fue arrebatado un cerco comunitario por parte de los Critto; además, quemaron el denominado "quincho comunitario". Un año más tarde, estos mismos terratenientes incendiaron la casa del comunero Juan Cruz, en la entrada de la base de Gonzalo. Otras de los y las comuneras afectadas fue la tutora/facilitadora intercultural Isabel Velardez y su compañero Ceferino Méndez, quienes fueron acusados de cuatrerismo -robo de animalespor parte, siempre, de la familia Critto.

En la base de Rearte Sur, desde el año 2001 en que se reorganizó la comunidad, se han presentado diversas denuncias contra familias comuneras, también por cuatrerismo y usurpación, por parte de los terratenientes López de Zavalía y sus encargados. Hacia 2007, el delegado Domingo Mamaní, el secretario general Carlos Villagra y los comuneros Mario Miguel y Celin Córdoba, entre otros, fueron denunciados por hacer uso de la llamada "mesada de abajo", de aproximadamente 9 hectáreas. Asimismo, fueron acusados de forma individual, otra vez, de cuatrerismo, asociación ilícita, usurpación de propiedad y ventas ilegales, lo que les ha generado causas judiciales hasta la actualidad. Por ejemplo, el delegado Domingo Mamaní me relató que ya suma 15 causas penales y 45 demandas civiles.
Si bien a largo de este conflicto han habido dos sobreseimientos a favor de la comunidad por la causa de "la mesada de abajo sur", hacia comienzos de 2019, los terratenientes López de Zavalía volvieron a apelar ante la justicia de la provincia de Tucumán.

Otro de los conflictos resonantes en la base de Rearte, sobre el que volveré, es la causa judicial por el conflicto territorial del comunero Donato Nievas y su familia contra el terrateniente Javier López de Zavalía. Tal como me contó Donato, esta causa tiene una historia que se remonta a comienzos del año 2000, durante el proceso de organización de la Comunidad Indígena, cuando tuvo el primer intento de desalojo. Luego se sucedieron dos más. El último contó con el fallo de la Corte Suprema de la Justicia de Tucumán en junio de 2017 en contra de la comunidad. Dicha resolución causó un gran impacto debido a que fue el puntapié que permitió que los terratenientes reiteraran sus amenazas, hostigamientos y activaran nuevamente causas, tanto contra el comunero Donato Nievas como contra las familias implicadas en los conflictos territoriales mencionados.

En la base de Tacanas Grandes, hacia el año 2005, encontramos las tentativas de desalojo a la exdelegada Pasquala Albero por parte de los terratenientes Saleme. Unos años después, los y las comuneras indicaron que esta familia terrateniente comenzó a vender las tierras a particulares con el fin de realizar un proyecto inmobiliario, denominado Club de Campo. Entre 1994 y 1996, en esta base también hubo hostigamientos por parte de los terratenientes Torino Guanuco. A causa de ellos, la comunera Antonia Quiroga se vio obligada a entregar algunos de sus cercos de siembra. También están los conflictos que sufrió la familia de la 
exdelegada de la base, Gladys Camacho, con la misma familia Torino Guanuco. Gladys me narró amenazas de muerte con látigos y revólveres y un juicio que tuvo que afrontar su hermano. En sus relatos señaló que a medida que el terrateniente alambraba el "campo abierto", ellos se fueron quedando sin espacio para sembrar y para que los animales pastaran. Desde 2015 en adelante, la familia terrateniente comenzó a vender las tierras, entre otros compradores, a un terrateniente de apellido Otero.

En la base de Hualinchay, hacia la década de 1990, los conflictos se dieron con los terratenientes Pena y luego con la familia de apellido Andrada. Tal como me han contado los tolombones, uno de sus miembros, Luis Andrada, estaba vinculado a la escuela de Hualinchay y ha sido delegado comunal de San Pedro de Colalao. Asimismo, me mencionaron que hacia 2010 en adelante comenzaron a ofrecer a las familias comuneras firmar comodatos (falsos) documento de alquiler o arriendo de la tierra-, lo cual implica una "trampa" debido a que se valen de las firmas para argumentar que son los dueños del territorio.

Como se puede apreciar, la comunidad de Tolombón posee una significativa cantidad de conflictos con familias terratenientes que han hostigado a las familias comuneras. Esto ha provocado que muchas familias, como indiqué, volvieran a firmar los mencionados comodatos (falsos) por miedo a represalias que otras se alejaran de la comunidad y tuvieran una participación menos activa en la Comisión Política de la misma. No obstante, un grupo de comuneros y comuneras buscó darle impulso a la organización comunal llamando nuevamente a elecciones y fomentando la participación de la gente. A este grupo se reintegró, como autoridad tradicional-cacique, Rufino Morales. Cuenta, además, con la participación de Isabel Velardez como tutora, la continuidad de Domingo Mamaní como delegado, en la base de Rearte -luego de unos meses sin estar en dicho cargo-, y de Carlos Villagra en su rol de secretario general. Asimismo, permanecen de forma activa comuneros y comuneras de las bases de apoyo, entre ellos Mercedes y Noemí Velardez, entre otros.

\section{Reorganización comunitaria, reivindicación identitaria y revalorización de materialidades}

La trayectoria que asumen las materialidades en el proceso de revitalización identitaria y reorganización comunitaria de Pueblo Tolombón comenzó con el proceso de reorganización de la comunidad indígena (fines de 1990-comienzos de 2000), cuando los y las tolombones comenzaron a recolectar, de forma individual, distintos objetos que encontraban mientras araban el territorio para sembrar. En numerosos relatos, como los de la autoridad tradicional Rufino Morales y los de su madre, Aurora Velardez, se puede apreciar que, si bien tiempo antes que se conforme la comunidad indígena se solían encontrar estos restos de piezas cerámicas, fue luego de este momento cuando les comenzaron a otorgar importancia:

Una vez encontramos en la casa de mi mamá una ollita, se ve que era una ollita de los indios [...]. Tenía dos orejitas arriba y dos orejitas abajo. Era pintada con negro, rojo y blanco. Todo con dibujos de los suris [...]. Esto fue hace muchos años, yo le cuento cuando tendríamos 15 años [...]. Antes uno no le llevaba el apunte, cómo le voy a decir, no les gustaba a nuestros padres que saquemos [...]. Y después como empezó Rufino, el abuelo Cosme, teníamos nosotros cosas guardadas. Hay que reguardarlas, decían, reservarlas [...]. La que sacó [refiere a parte de una ollita] Rufino 
es porque estuvo en el cerco. Allá en el cerco habíamos regado y eso el agüita había destapado y "mirá" le digo, "encontré una tapa redondita" [...]. Ahí estaba la olla. Después fue arando despacito [...] y se ha puesto a cavar y la sacaba pero apenas ya las iba sacando ya las tenía bien en bolsas plásticas. Así, que las iba sacando con tiempo y las iba metiendo dentro de la bolsa plástica, porque si usted deja que le dé el viento fuerte, se parte (Entrevista a Aurora Velardez, 24 de agosto de 2018, base Potrero).

En las expresiones "Antes uno no le llevaba el apunte, cómo le voy a decir, no les gustaba a nuestros padres que saquemos [...]. Y después como empezó Rufino, el abuelo Cosme, teníamos nosotros cosas guardadas. Hay que resguardarlas, decían, reservarlas" se observa un antes y un después respecto del tratamiento e importancia dada a los restos de piezas encontrados en el territorio. El "antes" refleja un contexto de negación hacia los pueblos originarios y la identidad indígena y de asimilación, donde predominaba un trato despectivo y de explotación laboral por parte de las familias terratenientes en tiempos anteriores a la década de 1990. "EI después" señala el momento de reconocimiento y de reivindicación político-cultural de su identidad y pertenencia territorial (Manzanello, 2020).

En este contexto, Cosme Morales, quien fuera la primera autoridad tradicional, realizaba visitas, casa por casa de los y las comuneras, informándoles sobre las leyes indígenas y el proceso de reorganización que ya se encontraba en marcha en otros pueblos diaguitas de los Valles Calchaquíes. Asimismo, Morales señalaba la importancia de revalorizar las tradiciones, costumbres y ceremonias que los identificaban como "indígenas", incluyendo a estos restos de piezas cerámicas, a los cuales hasta ese momento no se les prestaba demasiada atención. En otros términos, la idea de preservar estas piezas surgió a medida que los y las tolombones iniciaron el proceso de autorreconocimiento y de revalorización identitaria y que pudieron dejar atrás las connotaciones negativas y estigmatizadoras sobre su identidad -representadas bajo la categoría de "indios"-, cultura e historia.

Ello les permitió reapropiarse y reconectarse con su pasado y con los restos materiales presentes en el territorio. Si bien los y las tolombones señalaron: "siempre se han encontrado muchas ollitas", también destacaron que los restos de piezas empezaron a "aparecer" recién cuando se conformó la comunidad indígena: "Incluso empezaron a aparecer más [restos de ollitas, tinajas, morteritos, restos óseos] [...] desde que se conformó la Comunidad porque antes no aparecían muchas cosas", indicaron en varias ocasiones.

Entre las primeras experiencias de resguardo de materialidades se encuentra el Museo Comunitario Antonio Pasayo, construido en la base de Hualinchay, Tolombón. Este museo comunitario surgió hace aproximadamente una década gracias a la iniciativa de los y las comuneras de dicha base junto al apoyo de un equipo académico y de la fundación llamada Anku Ensamble 6 . El fin de la creación de este museo era homenajear al comunero y autoridad homónimo y preservar y otorgarles valor a los elementos -materiales e inmateriales- que forman parte de la cultura diaguita.

Antonio Pasayo es recordado en Tolombón como uno de los primeros caciques-autoridades de la actual base de Hualinchay que se reconoció como indígena y llevó adelante los primeros enfrentamientos contra los terratenientes de la zona, la familia Pena, cuando aún no se había conformado la Comunidad Indígena 
de Tolombón y, por lo tanto, Hualinchay no era aún una base territorial. Antonio Pasayo se convirtió así en una figura-emblema de la lucha de los y las tolombones por la defensa de su territorio. De esta forma, el museo comunitario es una muestra de este proceso de recuperación de los usos dados al territorio, ya que en él se exhiben diferentes tipos de objetos -tales como utensilios para cocinar, para realizar los viajes en mulas a través de los senderos comunitarios y abras para realizar los trueques, ropa, entre otros- con referencias y explicaciones de cómo eran utilizados y cómo muchos de estos elementos continúan vigentes actualmente. Así lo expresó la comunera Francisca Mamaní:

\section{El museo de Hualinchay es bonito, reivindica más lo que es de nosotros. Están las alforjas, hay un arco así que se llama chigua, ese es como una valija, metés todo ahí y no se te rompe nada. Están los chasme- ros que se les ponía a las mulas. Así se fue formando el museo y ahí hay algunas cosas de nosotros y eso nuevo es importante [...]. Antes sí la usaban más mayores [...] se ha sensibilizado más. (Entrevista a Francisca Mamaní, 20 de agosto de 2018, base Rearte)}

Como se aprecia, esta experiencia inicial del Museo Comunitario Antonio Pasayo ha sido valiosa para los y las tolombones dado que fue parte del momento en que comenzaron a reorganizarse y reconocerse como indígenas y a responder a los requisitos por parte del Estado nacional y provincial, como el relevamiento territorial, para la conformación de la Comunidad Indígena. De esta forma, emprendieron sus primeros ejercicios de reflexión sobre su cultura e historia al cobrar fuerza los recuerdos y argumentos sobre la importancia de los objetos encontrados, a la vez que asociaban sus años y experiencias vividas en el territorio con estos derechos de reconocimiento a la posesión y la preexistencia territorial.
El tipo de tratamiento y de reapropiación de forma colectiva-comunitaria de las materialidades se profundizó a medida que se incrementaron los conflictos territoriales, como el mencionado fallo de la Corte Suprema de Justicia de la provincia de Tucumán en contra del comunero Donato Nievas (base de Rearte) en 2017. A partir de ese momento se recrudecieron las acusaciones y amenazas de desalojo de las familias terratenientes, que argumentaban que "los comuneros y comuneras no eran los dueños de las tierras", que eran "usurpadores" y/o que "nunca hubo indios allí". En este sentido, los y las tolombones redefinieron y profundizaron su reconocimiento identitario, ya no solo autorreferenciándose como indígenas, sino como Pueblo Tolombón y acompañando este proceso con resignificaciones de sus prácticas, tradiciones y sus vínculos con el pasado -tanto de larga como de corta duración- (Manzanelli, 2021).

En otros términos, los y las comuneras comenzaron a replantearse las clasificaciones a través de las cuales han sido interpelados por el Estado nacional y provincial. Así, entendieron que la provincia de Tucumán, además de incumplir las leyes indigenistas, ha actuado en complicidad con los terratenientes al respaldar un modo liberal de tenencia de la tierra: la propiedad privada. En concordancia, han señalado que la noción de comunidad indígena reproduce lógicas colonialistas, occidentales y liberales, con un tratamiento paternalista y estigmatizante hacia los pueblos originarios. Esta crítica refiere que, si bien la categoría identitaria indígena ha logrado desterrar a la categoría indio -aunque no completamente-, también ha establecido una clasificación hegemónica (Manzanelli, 2020). 
Los y las tolombones fueron debatiendo en asambleas comunitarias cómo afrontar estas deslegitimaciones y amenazas de desalojo por parte de las familias terratenientes. Una de las formas consensuadas fue que las piezas encontradas debían contar con un espacio destinado especialmente a resguardarlas, que fuera reconocido e identificado por toda la comunidad como un espacio colectivo que cada comunero y comunera pudiera sentir como propio y acercar allí las piezas que se recolectasen en el territorio.

En este contexto, se realizaron distintas jornadas, como la mencionada experiencia comunitaria "Territorio de Memoria, Lucha y Resistencia Javier Chocobar" y el Taller Comunitario de Cerámica "Javier Chocobar" en la comunidad-pueblo vecina Los Chuschagasta. Allí, una de las jornadas estuvo dedicada a una charla donde participaron las autoridades tradicionales de la comunidad de Los Chuschagasta, Andrés Mamaní, y de Tolombón, Rufino Morales, sobre iconografía diaguita y cerámica. Se explicaron y mostraron fotos sobre los tipos de cerámica encontrados y sus decoraciones, en las que priman las formas simétricas y complementarias y figuras de animales entremezcladas, ejemplificadoras de una cosmovisión donde la continuidad entre los seres vivos ha sido constante. A medida que conversaban, surgieron enriquecedores comentarios por parte de la gente de la comunidad. Isabel y Mercedes Velardez, por ejemplo, hablaron sobre las piezas y sus usos e indicaron que continúan presentes en sus casas, muchas utilizadas y otras recolectadas.

Un año más tarde, en mayo y junio de 2018 , se realizaron dos talleres, uno en la base de Rearte y el segundo en la de Gonzalo, sobre la razón de reconocerse como Pueblo Tolombón.
Entre los aspectos trabajados se encontraba el de indagar sobre las materialidades -como las conanas y las parideras encontradas- como parte del fortalecimiento de la identidad. De la conversación emergieron los usos cotidianos de la cultura material y la relevancia de resguardarla de forma colectiva, ya que representa el "paso de los ancestros". Asimismo, en estos espacios de reflexión surgieron numerosos relatos que dieron cuenta de la carga simbólica asignada a estos restos, los cuales comenzaron a ser considerados "sagrados", de "valor" y "respeto", dado que allí reposan los espíritus de sus ancestros (Manzanelli, 2021).

Por último, el rescate y resguardo colectivo de los vestigios fue resignificado y revalorizado cuando la comunidad decidió apelar de forma colectiva la medida en los tribunales de la Corte Suprema de Buenos Aires. Esta nueva apelación instó a que los y las tolombones, en asambleas comunitarias, decidieran presentar como prueba dichos vestigios, a la par del trabajo de revalorización y de resguardo colectivo de estas materialidades. Considerando este escenario de judicialización, los y las tolombones comenzaron a fortalecer este proceso con el acompañamiento de un equipo de antropólogos(as). Recuerdo que durante mis estadías de trabajo de campo en la segunda mitad de 2018, los y las comuneras me indicaban de forma entusiasta que habían profundizado las tareas de conservación de las materialidades que iban encontrando y conversado sobre la forma correcta de resguardarlas -incluyendo morteros de gran tamaño-. Aurora Velardez, madre de Rufino Morales, me relató al respecto:

La vez pasada que vino un antropólogo le dijo [a Rufino]: "usted hizo mal en lavarlas, usted tenía que sacarle con un cepillito [...] igual están bien resguardadas". Él ha venido a Rearte [...] Creo que él ahora va a 
ir a Buenos Aires, ahora cuando vaya Rufino [...] para el conflicto de Donato [...]. Sacaron fotos. (Entrevista a Aurora Velardez, 24 de agosto de 2018, base Potrero)

Como se aprecia en el testimonio de Aurora Velardez, los restos de piezas cerámicas son tratados de una forma sumamente cuidadosa, para evitar que se rompan al sacarlos de la tierra donde se encuentran enterrados. Este especial interés hacia los vestigios se ha profundizado ante la posibilidad de presentación como prueba en la causa del comunero Donato Nievas y de la comunidad en sí.

\section{Materialidades y memoria}

Este mismo proceso de recuperación y de revalorización colectiva se ha observado en otras comunidades del Pueblo Diaguita, lo cual aparece claramente graficado en relatos que hacen referencia a los sitios y restos materiales del pasado encontrados en los territorios y al remarcar la diferencia con las formas en que la ciencia ha tratado y clasificado a los denominados restos arqueológicos. Por ejemplo, los restos mortales (esqueletos) u objetos que acompañaban a los cuerpos enterrados son elementos que pertenecen a las personas (muchos son considerados protectores y los objetos, ofrendas). Es decir, constituyen presencias vivas en la actualidad, necesarias para la reproducción social de estos pueblos y sus comunidades.

Estas materialidades se acompañan de prácticas culturales/identitarias y creencias indígenas ancestrales que aún están activas y que constituyen una base para el ordenamiento del territorio y las fuerzas que allí actúan e interactúan. De esta forma, por un lado, mediantes estas materialidades se cuidan los vínculos con los mayores y, por el otro, marcan su presencia en el territorio vinculándose y comunicándose con los vivos y con el entorno, al actuar e influir sobre la vida de las personas y sobre los fenómenos naturales. Son, así, una prueba de la preexistencia de estos pueblos y están acompañadas de saberes, prácticas y memoria (Amuedo, 2015; Corimayo \& Acuto, 2015; Huircapán, Jaramillo \& Acuto, 2017; Condori \& Santos Alancay, 2019; Zerpa, 2019).

La importancia dada a las materialidades por parte del Pueblo Tolombón -que desembocó en la decisión de resguardarlas de forma colectiva- emergió en varias oportunidades. Destaco algunas a modo de ejemplo. Una de las historias repetidas en la comunidad es la del momento en que la primera autoridad-cacique, Cosme Morales, encontró el esqueleto de un antepasado enterrado en una acequia que estaba cavando junto a su padre y otro comunero para la familia terrateniente de la base de Potrero de aquel momento, los López Pondal.

En el relato, los y las tolombones destacaron que, tras la sorpresa de encontar los restos óseos, Cosme, quien ya tenía conflictos con estos terratenientes por las obligaciones ${ }^{7}$ con las que los hacían trabajar, comenzó a preguntarle a su padre y al resto de los comuneros cómo podía ser que los terratenientes, "los ricos", insistieran en que los "indios" no existían si el esqueleto que se había encontrado era de un indio, por la altura y el tamaño que tenía. Los relatos señalan que Cosme y su padre dejaron allí al esqueleto, para que "descanse". Sin embargo, a partir de su descubrimiento, cobró fuerza la idea de cuestionar y refutar los dichos de los terratenientes, quienes siempre 
afirmaron que cuando ellos llegaron y se instalaron en el territorio, Tolombón se encontraba vacío, sin pobladores.

En otras ocasiones, los y las tolombones me contaron historias sobre lo que sucede cuando se levantan algunas piezas, en especial en el caso de urnas con restos óseos humanos. Para ellos(as), en estas se encuentran los espíritus de sus ancestros, de forma que, al sacarlas del territorio suelen "asustarlos", lo cual es interpretado como un mensaje de que ese ancestro, su espíritu y, por ende, ese vestigio necesita volver al territorio, al lugar al que pertenece. Asimismo, en los relatos señalaron que muchas veces "hay que enterrarlos". Al respecto, se puede observar que ciertas materialidades encontradas a lo largo del territorio son recuperadas, mientras que otras deben permanecer en él enterradas.

La importancia dada a las materialidades también se puede apreciar en los relatos sobre los antigales, es decir, restos de corrales y pircas que se encuentran en toda la zona. Resulta importante recordar que los antigales son también considerados espacios sagrados, utilizados por los antepasados como residencias o lugares de culto (Lanusse, 2007; Arenas \& Ataliva, 2017; Condori \& Santos Alancay, 2019; Mamaní, Chocobar \& Chocobar, 2019; Zerpa, 2019). En el caso de la base de Rearte, estos son resguardados por la comunidad, la cual evita que se intervengan o que las piezas arqueológicas allí presentes sean extraídas del territorio por personas ajenas.

Así, por ejemplo, una tarde, mientras estaba en la casa de la familia de Carlos Villagra, el secretario general de la comunidad, conversando sobre los conflictos territoriales, me llevaron a conocer uno de aquellos lugares, denominado Gran Mortero, ubicado cerca del puente de Rearte. Recuerdo que Marta Villagra -hermana de Carlos-amablemente me condujo en su auto a la casa de Domingo Mamaní dada la lejanía y, como indiqué, porque no hay transporte público que recorra ese trayecto. En el camino, mientras conversábamos, al pasar por el lugar donde se encuentra dicho vestigio, frenó el auto para preguntarme si alguna vez lo había visto. Le contesté que no, aunque había escuchado hablar de él en varios relatos. Fue así como Marta me invitó a conocerlo y me guió hasta el lugar. Noté su interés por que observase dicho mortero, el cual es una prueba irrefutable del paso de sus ancestros en el territorio y, por lo tanto, de la posesión y preexistencia territorial de la comunidad Tolombón.

Otro momento en el que pude apreciar la relevancia dada por los y las comuneras a los vestigios fue durante las caminatas con Francisca Mamaní cuando me acompañaba hasta la casa del comunero Donato Nievas, en Rearte. Ella me contaba la historia de su abuelo, quien había nacido y había sido criado allí. En el momento que pasamos cerca de una gran pirca, que aún podían vislumbrarse entre la gran cantidad de plantas y árboles, Francisca se detuvo para mostrarme unos restos de antigales, corrales que su abuelo había tenido que abandonar ante las amenazas de los terratenientes López de Zavalía.

De esta forma, estas memorias socializadas entre los y las tolombones muestran cómo el ejercicio de rescate y preservación de estos vestigios, restos óseos y piezas de cerámica comenzaron a ser resignificados y cómo emergieron recuerdos hilvanados sobre los mismos, relatos que forman parte de las memorias colectivas. Así, el comunero Juan 
Cruz, de la base de Gonzalo, se refirió a la importancia de conservar estos vestigios:

\begin{abstract}
Todo eso es lo que dejaron nuestros ancestros, todas esas piedritas, esos bationes, hay por ahí pedaceados, corral de piedra, vestigios, ahí hay vestigios, antigales [...] como que hay sepulturas, la forma de una sepultura de piedra [...]. Son sagrados, nosotros tenemos, tienen que respetar, son nuestros todo eso, de nuestros ancestros. Tenemos que cuidarlo [...]. Eso es nuestro, nadie que tocar [...] Le sirve a la comunidad para demostrar que eso es nuestro [...]. Eso es nuestro valor. Sí, yo respeto mucho eso y no voy a dejar sacar nada, ahí donde yo vivo, en ninguna parte. (Entrevista a Juan Cruz, 28 de julio de 2018, base Gonzalo)
\end{abstract}

Como se aprecia en este testimonio, estos vestigios deben ser conservados ya que son sagrados: representan el "valor" de la comunidad y merecen "respeto" pues evocan a los ancestros. La misma opinión fue señalada en los talleres. Esto explica la importancia extrema de cuidarlos y preservarlos y no permitir que "nadie", en referencia a personas ajenas a la comunidad, los robe o los extraiga del territorio, aspecto ya señalado en la descripción de los cuidados tomados para su conservación.

\section{Reflexiones finales}

A lo largo de este trabajo analicé los procesos de resignificación de materialidades y de creación de espacios de memoria en un ámbito de revalorización identitaria y territorial. Dado que las materialidades se encuentran cargadas de distintos sentidos e inmersas en procesos de simbolización y esferas de intercambios, el rol, la valoración, el tratamiento y los vínculos han ido cambiando. La trayectoria trazada a partir de los relatos y las prácticas que emergieron parte de una no preocupación explícita por conservarlas, pasando por resguardarlas de forma individual hasta la decisión de planificar este sitio de memoria de forma colectiva.

En primer lugar, si bien se aprecia que estas materialidades siempre han estado presentes en el territorio, en el momento de la reorganización comunitaria, conforme a un nuevo marco de derecho de reconocimiento a los pueblos indígenas y de los requisitos estatales, los y las comuneras señalaron que estas comenzaron a "aparecer cada vez más". Con ello creció el interés por conservarlas de forma individual. Las marcas de "antes" y "después" que establecen los y las comuneras en los relatos reflejan el pasaje de un contexto negacionista y asimilacionista de la identidad. En el primero -"antes"-, quienes disponían de las materialidades para demostrar resabios de un pasado eran solo los sectores dominantes, en concordancia con la categoría identitaria "indio". El segundo -"después"- está atravesado por un marco de derechos de reconocimiento a la diversidad de culturas, aunque sin efectividad en la práctica dado que los derechos territoriales continúan siendo vulnerados.

A medida que el proceso de reorganización comunitaria y reconocimiento identitario avanzó, tal como se mostró en el recorrido de toma de conciencia y de trabajo de concientización de Cosme Morales junto a otros comuneros y comuneras, el ejercicio de conservar las materialidades comenzó a ser colectivo y desembocó en la creación del Museo Comunitario Antonio Pasayo. Las materialidades asumieron un rol de ser diacríticos étnicos al ser ingresados en esferas de intercambio con categorías de valor otorgadas por las leyes para demostrar la identidad étnico-indígena, la posesión territorial-identitaria-cultural conti- 
nuada y la preexistencia. De esta forma, dicho museo se pensó como un espacio donde los elementos materiales son seleccionados, registrados y explicitados sus significados, por ejemplo, armando epígrafes con indicaciones y leyendas, inclusive para que personas que no integran la comunidad puedan visitarlo. Aquí las materialidades no pueden ser comprendidas sin considerar los sentidos propios de la comunidad -objetos de sus antepasados-ancestros-, aunque están permeadas de lógicas heredadas de una disposición occidentalizada de los objetos.

En segundo lugar, se planificó un proyecto de sitio de memoria a partir del resguardo colectivo de piezas que continúan apareciendo en el territorio. Este nuevo proyecto conjunto puede ser comprendido como una forma de ampliar y resignificar los modos de preservación de los restos de sus antepasados al reencontrar una nueva forma de vincularse con los mismos. De esta manera, esta no consistiría solamente en la exhibición de la cultura material, sino que se acompaña de un replanteamiento acerca de qué implica ser parte del Pueblo Tolombón, un cuestionamiento que se presenta en interacción con nuevos litigios judiciales por el territorio.

En consecuencia, en torno a la valorización de estas materialidades comienzan a resurgir memorias entrelazadas con las nociones de ancestralidad y de defensa del territorio, ejercicios de rememoración colectiva sobre los usos -que remiten a sus antepasados mayores y sus ancestros- y que incluyen historias que fueron contadas por ellos. Sin que las materialidades pierdan el carácter de diacríticos étnicos, toman fuerza los relatos que dan cuenta de la existencia de agencia y de distinciones en los estatus, por ejemplo, al momento de clasificarlas como sagradas. Resulta interesante resaltar que un elemento es asignado como sagrado a partir de la clasificación y el orden establecido por un colectivo, es decir, tienen un peso y un valor suficientemente representativos y sentidos como para ser recordados a través del tiempo y, por ende, ser conservados. Entre los sentidos y las características que le otorgan a dicha calidad de sacralidad, se encuentra que para los y las tolombones, los restos de sus antepasados poseen "valor" y "respeto", y reflejan el paso de sus ancestros; paso embebido de saberes, conocimientos y formas de experimentar el territorio. A su vez, los lugares donde son encontrados constituyen centros de espiritualidad, puntos de encuentro con sus ancestros, tal como lo refleja la revalorización de los vestigios como marcas de los antepasados y como puntos de protección.

Estas nuevas formas de valorización y jerarquización de materiales imbuidas de sacralidad e inalienabilidad -un objeto es inalienable por el tipo de valoración dada y no por una condición objetiva, natural o a priori- conllevan que los objetos son, por un lado, sacados de intercambios individualistas, que responden a la noción de propiedad privada, tal como ha sido considerada en sí la naturaleza y la forma de apropiación de las tierras y territorios por sectores dominantes y bajo lógicas coloniales. Por el otro, comienzan a tomar importancia materialidades que no pueden ser trasladadas, por ejemplo, el caso de las pircas asumidas como antigales o grandes morteros, así como otras que deben ser devueltas al territorio, como algunas piezas cerámicas con restos humanos, pues en caso contrario pueden generar enfermedades o "asustar" a los y las comuneras. 
Como se observó, las materialidades han sido históricamente apropiadas, valorizadas y mercantilizadas por sectores dominantes, pero en el marco del proceso de reivindicación identitaria y cultural, los y las tolombones las han considerado sagradas al integrarlas como parte de sus vínculos y cosmogonía. En consecuencia, se puede vislumbrar que la preservación de los vestigios encontrados no es estática o inerte, sino que se acompaña de vínculos y formas de vivenciar el territorio y los conocimientos locales transmitidos de forma oral. La construcción de estos espacios les ha posibilitado activar un trabajo de reflexión a partir del cual recuerdan y dan cuenta del lugar trascendental que posee el territorio y su disputa en la historia de los pueblos indígenas, punto que todavía hoy comparten con sus antepasados.

En otras palabras, se ha activado un proceso colectivo de territorialización que ha incluido acciones orientadas a resguardar, conservar y revalorizar elementos -materiales o inmateriales- que se encuentran vinculados con su identidad, cultura e historia, los cuales han sido negados o deslegitimadas por los sectores dominantes. En este sentido, los y las tolom- bones comenzaron a territorializar y materializar el pasado, lo que les permitió resignificarlo e impedir que se convirtiera en un tiempo inerte y desanclado del presente.

En tercer lugar, si en torno a las materialidades se disputan identidades por parte de quienes aspiran a imponer sus memorias e historias y legitimarse intentando invisibilizar a otras, los y las tolombones las resignificaron y las convirtieron en formas de marcar el territorio. Estas representan un lugar de enunciación y de cuestionamiento de la visión deslegitimante que mantienen los sectores dominantes sobre los pueblos originarios y su relación con el territorio -mirada que replica los discursos negacionistas y peyorativos sobre un pasado cosificado y sin relación con el presente-.

En suma, para los y las tolombones se trató de una práctica territorializadora que da cuenta de y legitima la continuidad y la ancestralidad en el territorio y la revalorización de sus vestigios como recursos culturales e identitarios. Así han demostrado su preexistencia e historia en el lugar, lo que les ha permitido sostener la expresión "siempre vivimos en el territorio", tal como lo han repetido en diversos testimonios. 


\section{Notas}

\begin{abstract}
${ }^{1}$ Terratenientes es una categoría usada por los y las tolombones para referir a familias no indígenas que históricamente han buscado usurpar sus territorios, acompañando sus pretensiones con situaciones de hostigamiento y violencia psicológica y física. A lo largo del trabajo se presenta esta categoría como principal aunque ha sido asociada con otras como "winkas" ("blancos") o "gringos", que también denotan la diferencia entre quienes son pobladores originarios y pertenecientes al Pueblo Tolombón y aquellos que han buscado apropiarse de sus territorios. Otros actores involucrados son los funcionarios del Poder Judicial de la provincia de Tucumán, identificados como parte del entramado de poder y con quienes estas familias terratenientes actúan en connivencia.
\end{abstract}

${ }^{2}$ A partir de fines del siglo XX, y tras las luchas de los pueblos originarios, como mencioné, emergió un nuevo marco de derecho denominado multiculturalismo neoliberal (Hale, 2002; Briones, 2005; Gordillo \& Hirsch, 2010). Dicho marco legal les ha otorgado a los pueblos el reconocimiento como sujetos de derecho con base en el respeto a la diversidad cultural y la diferencia étnica, dejando atrás las mencionadas retóricas de negación hacia los denominados "indios". Entre estas normativas se encuentran la incipiente Ley Nacional 23.302 (1985), que creó la figura etnogubernamental de las Comunidades Indígenas, y, nueve años después, el artículo 75 inciso 17 de la Constitución Nacional (1994), el cual reafirmó el reconocimiento a la posesión territorial y a la preexistencia de los pueblos indígenas respecto de la conformación del Estado nacional y provincial, avalando la noción de aboriginalidad. La idea de aboriginalidad reconoce la preexistencia de pobladores antes de la colonización española, cuyos descendientes son las familias indígenas actuales. La Ley 26.160 , que declara la emergencia en materia de posesión y propiedad de las tierras, reglamenta suspender la ejecución de sentencias, actos procesales o administrativos que tengan como objetivo el desalojo de las tierras tradicionalmente ocupadas por las comunidades originarias. Para ello, esta norma reglamenta el Programa de Relevamiento Territorial (Resolución 587/2007) que ordena al Instituto Nacional de Asuntos Indígenas (INAI) realizar el relevamiento técnico-jurídico-catastral de las "tierras actuales, tradicionales y públicas", fehacientemente acreditadas. En estos años, los y las tolombones, conforme a estas leyes nacionales - debido a que la provincia de Tucumán reconoció la prexistencia de los pueblos originarios recién a partir del año 2006-, se reorganizaron como comunidades indígenas en territorios delimitados a la par que los conflictos territoriales eran judicializados.

${ }^{3}$ El pensamiento occidental de la modernidad ha propiciado la idea de un universo natural de las cosas y la separación cuerpo/ mente, donde la mente se convirtió en el instrumento privilegiado para aprehender el mundo, superando los constreñimientos corporales y materiales. Asimismo, en el orden capitalista, la naturaleza fue alienada como propiedad privada. Quienes la poseen obtienen mayores retribuciones como resultado de su presencia extendida en el mundo material; aquellos que no poseen propiedad, por comparación, son convertidos en insustanciales. Dichas ideas se vinculan con la organización geopolítica y de dominio instaurada por el colonialismo, proceso de dominio político y militar que se desplegó para garantizar la explotación del trabajo y las riquezas de las colonias en beneficio del colonizador. Las élites coloniales (y luego republicanas) restringieron para sí la posesión de la mayor parte las tierras, incluyendo a las personas que las habitaban. De tal manera, solo algunas personas tenían autorizado el acceso a esta materialidad reconocida y, por ende, para ellos mismos; otros estaban alienados de ambos (Miller, 2005; Amuedo, 2015; Huircapán, Jaramillo \& Acuto, 2017).

${ }^{4}$ La investigadora Carolina Crespo (2011) ha indagado en los significados que adquiere dicha noción para las comunidades mapuche (Lago Puelo, Chubut) en un contexto de autorreconocimiento identitario y de reclamos por sus derechos a la propiedad colectiva de sus territorios - como la comunidad Cayún-. El término "autoctonía" apela al reconocimiento de quienes son parte de un espacio dado, que han nacido y han sido criados allí, a su origen, trayectorias y permanencias en el territorio. Se entrecruza con los discursos oficiales-hegemónicos sobre la autoctonía del pueblo mapuche en la región, muchos de los cuales han desconocido su posesión y preexistencia territorial.

${ }^{5}$ Los censos se realizan cada cuatro años, coincidiendo con las elecciones de autoridades. Dichos tiempos pueden ser menores o mayores, dependiendo de la situación de la comunidad y, especialmente, de los conflictos territoriales que debe afrontar. El último censo fue realizado hace dos años y se encuentra en proceso de reactualización.

${ }^{6}$ Espacio que se referencia de esta manera: "Utilizamos el conocimiento investigado y producido, para intervenir e involucrarnos en las diferentes realidades posibles de nuestras tierras. Compartimos nuestro trabajo colectivo a través de espectáculos, reuniones y exposiciones. Anku se moviliza a través de la autogestión, entendida colectiva y cooperativamente. Desde el arte y la antropología atacaremos a las academias institucionalizadas europeizantes y a toda la moral occidental represiva, en pos del resurgimiento de la forma ancestral de estar en el mundo" (fragmento extraído del link https://www.facebook.com/AnkuEnsamble).

${ }^{7}$ Las obligaciones y/o pastaje, las culaes fueron abolidas, consisten, en el primer caso, en un pago anual en forma de trabajos que incluían tareas como el cuidado del ganado, la preparación de la tierra, la siembra y la cosecha, actividades de construcción, la mantención de los corrales, tareas domésticas en la casa de los terratenientes, entre otras. En el segundo caso, los y las comuneras debían pagarle con una proporción de cabezas de ganado por familia. Esta modalidad de trabajo coercitivo representó una reactualización de los antiguos servicios personales que debían realizar las familias indígenas en las encomiendas (López, 2006; Lanusse, 2007; Boixadós, 2012; Calisaya et al., 2015; Espósito, 2017). 


\section{Referencias bibliográficas}

Acuto, F. \& Flores, C. (Comp.) (2019). Patrimonio y pueblos originarios: Patrimonio de los pueblos originarios. Buenos Aires: Universidad Nacional de La Matanza, Encuentro Nacional de Organizaciones Territoriales de Pueblos Originarios, Imago Mundi.

Acuto, F. A. \& Franco Salvi, V. (2015). Introducción: Arqueología y mundo material. En Acuto, F. A. \& Franco Salvi, V. (Eds.), Personas, cosas, relaciones: Reflexiones arqueológicas sobre las materialidades pasadas y presentes (pp. 9-34). Quito: Ediciones Abya-Yala.

Altschuler, B. (2013). Territorio y desarrollo: Aportes de la geografía y otras disciplinas para repensarlos. Theomai, 27/28, $64-79$.

Amuedo, C. (2015). Las vasijas y su potencial como sujetos estabilizadores de seres incompletos: Prácticas mortuorias de infantes durante el período Tardío en el Valle Calchaquí Norte. Estudios Atacameños. Arqueología y Antropología Surandinas, 50, 85-104.

Arenas, P. \& Ataliva, V. (2017). Las comunidades indígenas: Etnoterritorios, prácticas y saberes ancestrales. Tucumán, Buenos Aires: Ente Provincial Bicenteario.

Ataliva, V. (2008). Arqueología, memorias y procesos de marcación social (acerca de las prácticas sociales pos-genocidas en San Miguel de Tucumán). Grupo Interdisciplinario de Arqueología y Antropología de Tucumán, Facultad de Ciencias Naturales e Instituto M. Lilllo, Universidad Nacional de Tucumán.

Barabas, A. M. (2014). Etnoterritorios: legislaciones, problemáticas y nuevas experiencias. En Trinchero, H., Campos Muñoz, L. \& Valverde, S. (Coords.), Pueblos indígenas, Estados nacionales y fronteras: Tensiones y paradojas de los procesos de transición contemporáneos en América Latina, Tomo II (pp. 67-103). Buenos Aires: Facultad de Filosofía y Letras, Universidad de Buenos Aires. Recuperado de http://biblioteca.clacso.edu.ar/clacso/ se/20141119040550/Pueblos2.pdf.

Barth, F. (1976). Introducción. En Los grupos étnicos y sus fronteras. La organización social de las diferencias culturales (pp. 9-47). México: Fondo de Cultura Económica,

Benedetti, A. (2011). Territorio: Concepto integrador de la geografía contemporánea. En Souto, P. (Coord.), Territorio, lugar, paisaje: Prácticas y conceptos básicos en geografía. Buenos Aires: Facultad de Filosofía y Letras, Universidad de Buenos Aires.

Bermejo, T. \& Cortés Aliaga, G. (2019). Museos híbridos, feministas, descolonizados. Caiana. Revista de Historia del Arte y Cultura Visual del Centro Argentino de Investigadores de Arte, 14, 56-62.

Boixadós, R. (2012). Dilemas y discursos sobre la continuidad de los pueblos de indios de la jurisdicción de La Rioja bajo las reformas borbónicas. Mundo Agrario, 13(25).

Briones, C. (2005). Formaciones de alteridad: Contextos globales, procesos nacionales y provinciales. En Briones, C. (Ed.), Cartografías argentinas: Políticas indigenistas y formaciones provinciales de alteridad (pp. 11-44). Buenos Aires: Antropofagia.

Calisaya, A., Del Bel E., Heredia, I., Lund, J., Nassif, S. \& Wieder, D. (2015). Huellas y memorias. En Racedo, J. (Ed.), Conociendo la comunidad indígena Los Chuschagasta: Tierra, organización comunitaria e identidad (pp. 12-26). San Miguel de Tucumán: Facultad de Filosofía y Letras, Universidad Nacional de Tucumán.

Chaparro, M. G. (2019). La construcción de un Espacio de Memoria en un ex Centro Clandestino de Detención, Tortura y Desaparición de Personas en Olavarría (Argentina). InterSecciones en Antropología, 20(2). Recuperado a partir de https://interseccionesantro.soc.unicen. edu.ar/index.php/intersecciones/article/view/451.

Condori, E. \& Santos Alancay, E. (2019). Territorio, identidad, preexistencia y patrimonio desde la pespectiva del Pueblo Nación Diaguita. En Acuto, F. \& Flores, C. (Comps.), Patrimonio y pueblos originarios: Patrimonio de los pueblos originarios (pp. 121-131). Buenos Aires: Universidad Nacional de La Matanza, Encuentro Nacional de Organizaciones Territoriales de Pueblos Originarios, Imago Mundi.

Corimayo, H. \& Acuto, F. (2015). Saber indígena y saber arqueológico en diálogo: Interpretando la cultura material diaguitakallchaquí. En Acuto, F. \& Franco Salvi, V. L. (Comps.), Personas, cosas, relaciones: Reflexiones arqueológicas sobre las materialidades pasadas y presentes (pp. 249-297). Quito: Abya-Yala.

Crespo, C. (2011). Patrimonio arqueológico, memoria y territorio: Procesos de autoctonización entre los mapuches de Lago Puelo, Chubut (Patagonia, Argentina). Frontera del Norte, 23(45), 231-256. (2018). Memorias dolorosas, memorias del dolor: Reflexiones y debates mapuche sobre la restitución de restos humanos mapuche-tehuelche en la Patagonia argentina. Estudios Atacameños. Arqueología y Antropología Surandinas [en línea], 60, 257-272.

Delrio, W. (2010). Memorias de expropiación: Sometimientos e incorporación indígena en la Patagonia (1872-1943). Bernal: Universidad Nacional de Quilmes.

Enderé, M. L. \& Chaparro, M. G. (2013). El rol del patrimonio arqueológico en la valorización social del pasado. En Williams, V. I. \& Cremonte, M. B. (Comps.), Al borde del imperio: Paisajes sociales, materialidad y memoria en áreas periféricas del noroeste argentino (pp. 109-140). Buenos Aires: Sociedad Argentina de Antropología.

Escobar, A. (2000). El lugar de la naturaleza y la naturaleza del lugar: ¿Globalización o postdesarrollo? En Edgardo Larden (Ed.), La colonialidad del saber: Eurocentrismo y ciencias sociales: Perspectivas latinoamericanas. Buenos Aires: Consejo Latinoamericano de Ciencias Sociales. Recuperado de http://bibliotecavirtual.clacso.org.ar/clacso/ sursur/20100708045100/7_escobar.pdf.

Escolar, D. (2003). Arqueólogos y brujos: La disputa por la imaginación histórica en la etnogénesis huarpe. Relaciones de la Sociedad Argentina de Antropología, 28, 23-43. Recuperado de http://sedici.unlp.edu.ar/handle/10915/24971

Espósito, G. (2017). La polis colla: Tierras, comunidades y política en la Quebrada de Humahuaca. Buenos Aires: Prometeo.

Gordillo, G. \& Hirsch, S. (Eds.) (2010). Movilizaciones indígenas e identidades en disputa. Buenos Aires: La Crujía.

Guber, R. (2011). La etnografía. Buenos Aires: Siglo XXI.

Hale, C. (2002). ¿Puede el multiculturalismo ser una amenaza? Gobernanza, derechos culturales y política de la identidad. En Lagos, 
M. L. \& Calla. P. (Comps.), Antropología del Estado: Dominación y prácticas contestatorias en América Latina Guatemala (pp. 286-346). La Paz: Informe de Desarrollo Humano/ Programa de las Naciones Unidas para el Desarrollo.

Haesbaert, R. (2004). O mito da desterritorialização: Do "fim dos territórios" à multiterritorialidade. Río de Janeiro: Bertrand.

Huircapán, D., Jaramillo, A. \& Acuto, F. A. (2017). Reflexiones interculturales sobre la restitución de restos humanos indígenas. Cuadernos del Instituto Nacional de Antropología y Pensamiento Latinoamericano, 26(1), 57-75.

Jelin, E. (2004). Reflexiones (localizadas) sobre el tiempo y el espacio. En Grimson, A. et al., La cultura en las crisis latinoamericanas (pp. 237248). Buenos Aires: Consejo Latinoamericano de Ciencias Sociales. (2017). La lucha por el pasado: Cómo construimos la memoria social. Buenos Aires: Siglo XXI.

Kopyttof, I. (1986). La biografía cultural de las cosas: La mercantilización como proceso. En Appadurai, A. (Ed.), La vida social de las cosas: Perspectiva cultural de las mercancías (pp. 89-122). Cambridge: Cambridge University Press.

Lanusse, P. (2007). Memoria y alteridades indígenas en Cachi, provincia de Salta. Tesis de Grado, Licenciatura en Ciencias Antropológicas. Facultad de Filosofía y Letras, Universidad de Buenos Aires, Buenos Aires.

Lefebvre, H. (1991) [1974]. The production of space. Oxford: Blackwell.

Longo, A. (2010). Pueblos indígenas y Estado-nación en la actualidad: Construcción de alteridades en las disputas por el pasado: Los niños de Llullaillaco - YuyaiYakuWawakuna. Trabajo final del Seminario de Antropología Social: Alteridades, Estados y gubernamentalidad neoliberal, Prof. Morita Carrasco. Facultad de Filosofía y Letras, Universidad de Buenos Aires, Buenos Aires.

López, C. (2006). Tierras comunales, tierras fiscales: El tránsito del orden colonial a la revolución. Revista Andina, 43.

Lopes de Souza, M. J. (2001). O território: Sobre espaço e poder: Autonomia e desenvolvimento. En Castro, I. E. de, Gomes, P. C. da C. \& Corrêa, R. L. (Orgs.), Geografia: Conceitos e temas. Río de Janeiro: Bertrand.

Maidana, C. A. (2011). Migrantes tobas (qom), procesos de territorialización y construcción de identidades. Tesis de Doctorado. Universidad Nacional de La Plata, Buenos Aires.

Mamaní, A., Chocobar, A. \& Chocobar, N. (2019). Proyecto "Territorio de memoria, lucha y resistencia Javier Chocobar", Comunidad Los Chuschagastas, Pueblo Nación Diaguita. En Acuto, F. \& Flores, C. (Comps.), Patrimonio y pueblos originarios: Patrimonio de los pueblos originarios (pp. 107-123). Buenos Aires: Universidad Nacional de La Matanza, Encuentro Nacional de Organizaciones Territoriales de Pueblos Originarios, Imago Mundi.

Manzanelli, M. (2020). "Somos pueblo, con autodeterminación libre y colectiva": Reivindicaciones identitarias-organizativas de Los Chuschagasta y Tolombón. Tabula Rasa, 34, 109-130. Recuperado de https://doi.org/10.25058/20112742.n34.06

(2021). Lecturas del pasado en procesos de reafirmación comunitaria contemporáneos: El caso de la Comunidad Pueblo Tolombón (Valle de Choromoro, Argentina). Revista de Historia Regional y Local, 13(26), 37-72. Recuperado de https://doi. org/10.15446/historelo.v13n26.85410

Pizarro, C. (2006). Tras las huellas de la identidad en los relatos sobre el pasado. Cuadernos de Antropología Social, 24, 113-130. Recuperado de https://doi.org/10.34096/cas.i24.4411

Miller, D. (2005). Materiality: An introduction. En Miller, D. (Ed.), Materiality (pp. 1-50). Durham: Duke University Press.

Myers, F. (1996). Introduction: The empire of things (pp. 3-65). En Myers, F. (Ed.), Empire of things. Santa Fe: School of American Research Press, James Currey.

Morales, H. \& Quiroz, L. (2017). Indígenas desencajados y museo de San Pedro de Atacama. Revista Chilena de Antropología, 36, 344-361. doi: 10.5354/0719-1472.2017.47499

Puebla, M. F. \& Ramírez, N. (2020). Reconsideraciones, análisis y perspectivas futuras de la museología comunitaria: Reflexiones a partir del caso de El Rosario (Hidalgo, México). Memorias. Revista Digital de Historia y Arqueología desde el Caribe Colombiano, 16(40), 8-32.

Ramos, A. M. (2016). La memoria como objeto de reflexión: Recortando una definición en movimiento. En Ramos, A. M., Crespo, C. \& Tozzini, M. A. (Comps.), Memorias en lucha: Recuerdos y silencios en contextos de subordinación y alteridad (pp. 51-71). Viedma: Universidad Nacional de Río Negro.

Ramos, A. M., Crespo, C. \& Tozzini, M. A. (2016). En busca de recuerdos ¿perdidos?: Mapeando memorias, silencios y poder. En Ramos, A. M., Crespo, C. \& Tozzini, M. A. (Comps.), Memorias en lucha: Recuerdos y silencios en contextos de subordinación y alteridad (pp. 13-50). Viedma: Universidad Nacional de Río Negro.

Salazar, J. \& Franco Salvi, V. L. (2015). Materialidad cotidiana, memoria y reproducción social en sociedades aldeanas del sur andino durante el primer milenio d.C. En Salazar, J. \& Franco Salvi, V. L., El rol de los objetos en la comprensión del pasado. Propuestas teóricometodológicas para el estudio de la materialidad en Arqueología (pp. 213-248). Quito: Abya-Yala.

Schneider, S. \& Peyré Tartaruga, I. (2006). Territorio y enfoque territorial: De las referencias cognitivas a los aportes aplicados al análisis de los procesos sociales rurales. En Manzanal, M., Neiman, G. \& Lattuada, M. (Orgs.), Desarrollo rural: Organizaciones, instituciones y territorio (pp. 71-102). Buenos Aires: Ciccus.

Tamagno, L., Maidana, C. A. \& Martínez, A. (2015). Rebeliones indígenas, movimientos socio religiosos y procesos de territorialización: El dios Luciano y la Iglesia Evangélica Unida en Argentina. Tabula Rasa, 22, 147-166. doi: https://doi.org/10.25058/20112742.27

Verdery, K. (1999). Dead bodies animate the study of politics. En Verdery, K., The political lives of dead bodies: Reburial and postsocialist change (pp. 23-53). Nueva York: Columbia University Press.

Zerpa, G. (2019). Defendiendo los sitios sagrados del Pueblo Tastil. En Acuto, F. \& Flores, C. (Comps.), Patrimonio y pueblos originarios: Patrimonio de los pueblos originarios (pp. 131-137). Buenos Aires: Universidad Nacional de La Matanza, Encuentro Nacional de Organizaciones Territoriales de Pueblos Originarios, Imago Mundi. 